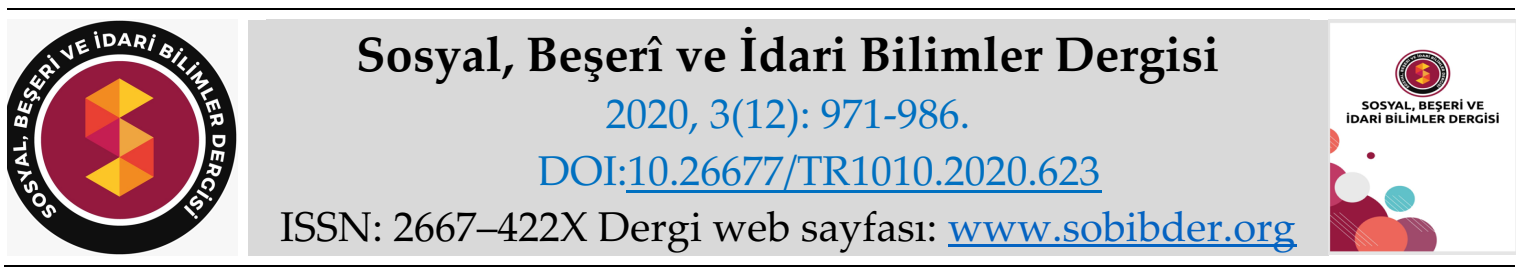

ARAȘTIRMA MAKALESI

\title{
TV Yemek Programlarının Popüler Kültür Algısı ve Gençlerin Eğitim-Meslek Seçimlerine Etkileri
}

Dr. Öğr. Üyesi Tuba ALDEMIR, İstanbul Esenyurt Üniversitesi, Meslek Yüksekokulu, İstanbul, e-posta: tubaaldemir@yahoo.com

ORCID: https://orcid.org/0000-0001-7419-3640

Dr. Öğr. Üyesi Merve IŞKIN, İstanbul Esenyurt Üniversitesi, Meslek Yüksekokulu, İstanbul, eposta: merveiskin25@gmail.com

ORCID: https://orcid.org/0000-0002-4748-0422

Dr. Ümit ŞENGEL, Sakarya Uygulamalı Bilimler Üniversitesi, Turizm Fakültesi, Sakarya, e-posta: umitsengel@gmail.com

ORCID: https://orcid.org/0000-0003-1284-836X

Öz

Son yıllarda görsel medyadaki bazı programlarda niceliksel artışlar yaşanmaktadır. Belirli formatta programların reyting ve popüler kültür gibi amaçlarla farklı medya platformlarında yoğunlaştığı görülmektedir. Bu çalışmada Türkiye'deki TV yemek programlarının popüler kültür algısı ile bu programların gençler üzerindeki etkilerinin tespit edilmesi amaçlanmıştır. Araştırmada nitel araştırma yöntemlerinden yararlanılmış, veri toplama aracı olarak odak grup görüşmesi kullanılmıştır. İstanbul Esenyurt Üniversitesi Meslek Yüksekokulu Aşçlık programı öğrencilerinden veriler elde edilmiştir. İki paralel oturumda 8 kişi olacak şekilde toplam 16 kişi araştırmanın veri toplama sürecine dâhil edilmiştir. Analizler MAXQDA nitel analiz programı yardımıyla analiz edilmiştir. Araştırma sonuçlarına göre gençlerin artan TV yemek programlarını popüler kültürün bir unsuru olarak gördükleri tespit edilmiştir. Ayrıca bu programların öğrencilerin bölüm tercihi ve mesleki bağlllıklarını etkilediği de çalışmanın önemli sonuçlarındandır.

Anahtar Kelimeler: TV Yemek Programları, Popüler Kültür, Odak Grup Görüşmesi, Gastronomi. Makale Gönderme Tarihi: 25.09.2020

Makale Kabul Tarihi: 02.12.2020

\section{Önerilen Atıf:}

Aldemir, T., Işkın, M. ve Şengel, Ü. (2020). TV Yemek Programlarının Popüler Kültür Algısı ve Gençlerin Eğitim-Meslek Seçimlerine Etkileri, Sosyal, Beşeri ve İdari Bilimler Dergisi, 3(12): 971-986. (c) 2020 Sosyal, Beşerî ve İdari Bilimler Dergisi. 


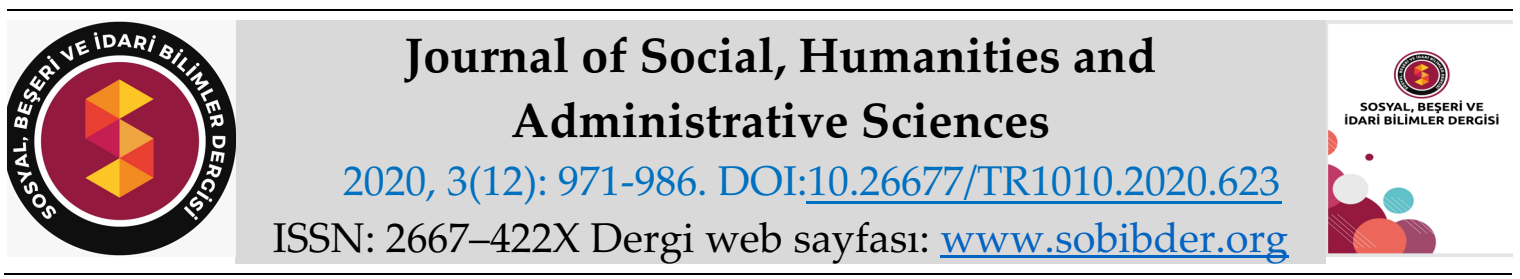

RESEARCH PAPER

\title{
Popular Culture Perception of TV Food Programs and Their Impact on Young People's Education-Profession Choices
}

Assistant Prof. Dr. Tuba ALDEMİ, İstanbul Esenyurt University, Vocational School, İstanbul, email: tubaaldemir@yahoo.com

ORCID: https://orcid.org/0000-0001-7419-3640

Assistant Prof. Dr. Merve IŞKIN, İstanbul Esenyurt University, Vocational School, İstanbul, email: merveiskin25@gmail.com

ORCID: https://orcid.org/0000-0002-4748-0422

Dr. Ümit ŞENGEL, Sakarya University of Applied Sciences, Faculty of Tourism, Sakarya, e-mail: umitsengel@gmail.com

ORCID: https://orcid.org/0000-0003-1284-836X

\begin{abstract}
In recent years, there has been a quantitative increase in some programs in visual media. It is seen that the programs in certain format are concentrated on different media platforms for reasons such as ratings and popular culture. In this study, popular culture perception of TV food program in Turkey and aimed to determine the effects on young people of these programs. Qualitative research methods were used in the research. Focus group discussion was used as data collection tool. Data were obtained from Istanbul Esenyurt University Culinary Department students. A total of 16 people, including 8 people in two parallel sessions, were included in the data collection process of the study. Analyzes were analyzed with the help of MAXQDA qualitative analysis program. According to the results, it was determined that young people saw increasing TV cooking programs as an element of popular culture. In addition, one of the important results of the study that these programs affect the preference of students and their professional commitment.
\end{abstract}

Keywords: TV Food Programs, Popular Culture, Focus Group Discussion, Gastronomy.

Received: 25.09 .2020

Accepted: 02.12.2020

\section{Suggested Citation:}

Aldemir, T., Işkın, M. and Şengel, Ü. (2020). Popular Culture Perception of TV Food Programs and Their Impact on Young People's Education-Profession Choices, Journal of Social, Humanities and Administrative Sciences, 3(12): 971-986.

(C) 2020 Sosyal, Beşerî ve İdari Bilimler Dergisi. 


\section{Gíriş}

Türkiye' de başta televizyon (TV) olmak üzere zaman zaman görsel medyada bazı programların sayısında ciddi artışlar yaşanmaktadır. Bu artışların farklı sebepleri bulunmaktadır. TV programlarının reyting kaygısıyla yapıldığı düşünüldügünde, belli periyotlarda benzer programların farklı kanallarda yayınlanması düşündürücüdür. Bu bilgiler ışığında son yıllarda Türkiye'de yayın yapan TV kanallarında yemek programları ile sıklıkla karşılaşmaktadır. İlgili programlardaki artışta reyting beklentilerinin yanı sıra son yıllarda gastronomi kavramının kavramsal, metodolojik ve sektörel gelişiminin de etkileri olduğu düşünülmektedir. Araştırmanın sonuçlarına da yansıyan bu tespitler ile ilgili ileriki dönemlerde sorun yaşanmaması için tedbirlerin alınması gerekmektedir.

Televizyonun kitle iletişim araçları içinde çok ucuz ve yaygın olması, kültürel değişme/değişim bakımından televizyonun popüler kültürün en belirgin taşıyıcıları haline gelmesine aracılık etmiştir. Dünyada daha erken olmakla birlikte, 1990'lı yıllarda Türkiye'de çok sayıda özel televizyon kanalı yayın hayatına başlamıştır. Özel kanallardaki yayınlar ve reyting yarışları bir toplumsal değişimi beraberinde getirmiş ve bu yıllardan sonra televizyon yayıncılığındaki gelişmelere de bağlı olarak popüler kültür tartışmaları ağırlık kazanmaya başlamıştır. Bu bakımdan ucuz ve evlerde uygulanan bir faaliyet olması nedeniyle televizyonun izleyicilere olan etkiler bakımından sahip olduğu özellikler, onu kitle kültürünün temel taşıyıcılarında bir haline getirmiştir. Bu özellikler (Yıldız, 2004);

- Homojenleştirici

- Siradanlaştırıcı

- Yabancilaştırıcı

Küreselleşme sürecinde yaşanan gelişmeler neticesinde artık daha fazla insan daha uzak mesafelere seyahat edebilir konuma gelmiştir. $\mathrm{Bu}$ durum gastronomi açısından değerlendirildiğinde geniş bir yiyecek yelpazesini deneyimleme fırsatından yararlanmanın yolunun açıldığı anlamına gelmektedir. Medya, gazete, dergi ve televizyon kanallarında gıda alanında bir patlama olmuş ve perakende sektörü canlanan ilginin yarattığı talebe cevap vermiştir. Süpermarketlerde ve diğer mağazalarda sürekli büyüyen bir ürün yelpazesi mevcut olmakta, ekipman ve mutfak eşyaları bulmak daha kolay hale gelmekte ve gittikçe restoranlarda daha fazla yemek deneyimlenmektedir. Bu da konuyla ilgili yeni fırsatlar sunmaktadır. Yeni gıda, teknik ve stiller ülke kültürüne adapte edildikçe birer norm ve kültürel öğe haline gelebilir (Judelson, 1997).

Gastronomik unsurlar ile popüler kültürün temel unsurlarından olan kitle iletişim araçları arasında yakın bir ilişki ortaya çıkmaya başlamıştır. Hem televizyonların hem de gastronomik öğelerin görsel argümanlar içermesi bu ilişkiyi daha da derinleştirmektedir. Bu nedenle çok sayıda TV yayınlarında gastronomik öğe kullanılmaya başlanmışıı. Gastronomi turizminin ve gastronomi eğitiminin yaygınlık kazanmaya başlamasıyla birlikte TV kanallarında üretim ve teknik bilgilerin de olduğu yeme-içme içerikli programları düzenlenmeye başlamıştır (Kurtçu, 2015). Küreselleşmenin sahip olduğu bazı özellikler belli konularda sınırları ortadan kaldırarak benzer nitelikteki uygulamaların ortaya çıkmasına zemin hazırlamıştır. Özellikle homojenleştirici etki; beklenti, memnuniyet ve fayda konularında insanların benzer düşünmelerini beraberinde getirmiştir. Küreselleşmenin bu etkisi birçok alanda olduğu gibi yaşam biçimleri ve değer yargıları benzeşen kozmopolitan insanların artışına neden olmuştur. Farklı ülkelerde veya aynı ülkenin farklı görsel medya kanallarında formatları benzeşen yemek programlarının olması bu durumun bir sonucu olarak ifade edilebilir (Kanık, 2016).

Bu çalışmada TV yemek programlarının popüler kültür algısı ve gençler üzerine etkisinin tespit edilmesi amaçlanmıştır. Ayrıca yemek programlarının, popüler kültürün oluşumunda ve 
aktarılmasındaki rolü incelenmiştir. Günlük yaşamda eğlenceden tüketim tercihlerine kadar birçok konuda kitleler üzerinde yönlendirici bir etkiye sahip olan TV yemek programlarının popüler kültürle ilişkisinin araştırılması oldukça önemlidir. Çünkü bu programların reyting ve popüler kültür gibi amaçlarla yapılması gençler üzerinde olumsuz etkilere neden olabilmektedir. Bu bilgiler ışığında, yapılan bu çalışmanın teorik ve toplumsal pratikler bağlamında literatüre katkı sağlayacağı düşünülmektedir.

\section{LITERATÜR TARAMASI ve ARAŞTIRMA SORULARI}

Popüler kültür kavramsal olarak geniş kesimlerin zevklerine uygun olan ve yaygın kültürel unsurlar olarak tanımlanmıştır (Kösoğlu, 1992). Popüler kültür kavramı toplumdaki bireyleri yaş, cinsiyet, sınıf farkı gibi demografik unsurları gözetmeksizin ortak bir noktada toplayıp ortak bir bakış açısı oluşturmuştur. Kavram başka bir ifadeyle, toplumdaki farklı sosyo-ekonomik düzeydeki bireyleri bir araya getiren ortak bir kılavuz olarak ele alınabilir. Gündelik yaşamın kültürü olan popüler kültür; yaşam pratiklerimizi şekillendirmekte, hayatın her alanına nüfuz etmektedir (Tezer, 2013).

Popüler kültürle ilgili bazı tanımlamalar olmakla birlikte, kavramın tanımlanması zordur. Genellikle gelip-geçici ve gündelik bir hayat kültürü olan kavram, içinde müzik, yeme-içme, giyime ve spor unsurları içeren bir çeşitliliğe sahiptir. Gündelik bir tüketim kültürü olmanın yanı sıra, kitleleri eğlendirerek, onların üzerinde yönlendirici bir role sahip olmaktadır. Bu durum popüler kültüre sürekli değişim ve gelişim içerisinde olan bir kimlik kazandırmaktadır. Çünkü popülerliğini korumak, tüketiciye istediğinde yeniyi sunmakla eşdeğerdir (Karaduman, 2017).

Popüler kültürün geçmişi çok eskilere dayanmakla birlikte, teknolojik gelişmeler doğrultusunda günümüzde daha çok önem kazanan bir olgu haline gelmiştir. Popüler kültüre konu olan ürünlerin oluşumunda ve aktarılmasında TV başta olmak üzere kitle iletişim araçlarının rolü oldukça büyüktür. Eğitim düzeyi, dünya görüşü, gelir durumu, cinsiyet ve yaş gibi tanımlayıcı özellikleri farklı olan milyonlarca insan, TV sayesinde popüler kültürle tanışmakta ve bu oluşumun aktarımında aktif rol almaktadır (Karaduman, 2017). Televizyon programları üzerinden verilen mesajlar izleyicilerin norm, tutum, değer yargıları ve inançlarını etkileyebilen ikna kapasitesi yüksek araçlardır (Shrum, 2009).

Popüler kültürün "halk tarafından sevilen" tanımı ile güçlü bir ilişki içerisinde olan medya sektörü burada zikredilen sevgiyi daha da etkin hale getirmektedir. Bu ilişki ve medyanın rolü insanların yaşam biçimlerini değiştirerek; algı, nefret, sevgi, gündelik yaşam ve siyasi-sosyal düşüncelerini sahip olduğu güce göre şekillendirmektedir. Böylece medya ve popüler kültürün birlikte anılması doğal bir hal almaktadır (Geçer, 2013). Dolayısıyla, popüler kültürün olgunlaşması, iletişim teknolojileri ile bu teknolojinin yarattığ yoğun etkileşim ve hızlı iletişime dayalı olarak gerçekleşmektedir (Şentürk, 2007).

Gündelik hayatı ve kültürel alanı etkileyen TV programları bu dönemde dünyadaki boş zaman aktiviteleri içerisinde üst sırada yerini korumaktadır. Diğer yandan son 20 yılda gastronominin giderek önem kazanması, turizm ve eğitim gibi alanlardaki gelişmeler doğrultusunda medyanın ilgisi bu alana kaymış ve gastronomiyi konu alan televizyon programlarının sayısı giderek artmıştır (Şenel ve Yılmaz, 2017). COVID-19 pandemisi nedeniyle bir duraklama süreci içine giren bu programların pandemi sonrası tekrar yaygınlık kazanacağı düşünülmektedir.

TV yemek programları ve yarışmalara talep, tüm dünyada olduğu gibi ülkemizde de hızlı bir ivme kazanmıştır. Bu yayınlar, televizyon kanallarının reyting için verdikleri mücadelede önemli bir yer tutmaktadır. İlgili programlarda Türk ve dünya mutfaklarına ait uygulamaların yapılması toplumun farklı kesimlerinden izleyici kitlesinin oluşmasına neden olmaktadır. TV 
yemek programları seyirciler açısından eğlenceli vakit geçirmenin yanı sıra, yiyecek veya içeceklerin hazırlanması, pişirilmesi, sunumuna dair teknik ve pratik tavsiyelerin öğrenilebileceği bir eğitim ortamı gibi bir işleve de sahiptir. Programlarda alanında eğitimli ve/veya sektör tecrübesi yüksek ünlü şefler bulunması da gençler başta olmak üzere toplumun farklı kesimlerinden izleyicileri mutfağa girme noktasında teşvik etmektedir (Ertopçu ve Görkem, 2019).

Programlarda beceri, deneyim ve bilgi birikimlerini paylaşan ünlü şefler, ilgili alanlara ilgi duyan bireyler için birer rol model konumuna gelmektedir (Boyle ve Kelly, 2010). TV yemek programlarının işleyişi sırasında temizlik, iş güvenliği, hijyen, doğal ve sağlıklı beslenme uygulamaları gibi toplumun geneline hitap edebilecek normları ve mesleki etik kuralları içerme sorumluluğu gibi katkıları konuyu araştırmaya değer hale getirmektedir. Böylece, üretici (yarışma, medya platformu) ile tüketici (izleyici) arasındaki etkileşimden beslenen programlar sosyal sorumluluk ve mesleki etik ilkelerine uygun hareket etmek zorundadır (Ertopçu ve Görkem, 2019).

Son 20 yılda Fransa, Avustralya ve Amerika gibi ülkelerde gastronomiyi konu alan TV programları artmakta, bunlar yemek ve mutfağa ilişkin global düzeyde yoğun bir ilginin oluşmasını sağlamaktadır (Matwick ve Matwick, 2014). Türkiye'de geçmişi çok eski olmamakla birlikte yemek programlarının olduğu söylenebilir. 2015 sonrası dönemde programların daha fazla artış eğilimindedir.

Türkiye'deki TV programlarının önemli bir kısmı dünyanın farklı ülkelerindeki programların uyarlaması şeklindedir. Bu programlarda mutfak bilgisi ve gastronomi sevgisi gibi hususlar ön plana çıktı̆̆ı gibi, özellikle yarışma formatındaki programlarda yarışmacıların kavga ve üslupları da ön plana çıkmaktadır. Bununla birlikte katılımcı şeflerin ve jürilerin bilgi ve becerileri insanlar için öğretici unsurların ortaya çıkmasını sağlamaktadır. Bu sayede izleyiciler hem eğlenmekte hem de öğrenmektedir. Globalleşme ile birlikte postmodern ve çokkimliklilik gibi nitelikleriyle yeni bir kimlik kazanan televizyon izleyiciliği, programların niteliğini belirleyen önemli bir unsurdur. Programlar bu unsurlar nedeniyle çoğul bir anlayışı tekil anlayışlara tercih etmektedir. Özellikle kimliksel bir dönüşümü ifade eden yarışmalarda tecrübe, cinsiyet, etno-kültür ve yaş gibi farklı unsurlarla farklı bir etkileşim oluşturulmaya çalışılmaktadır (Köksalan, 2009).

Modern dünyanın giderek hızlandığı günümüzde yemek, yemek odaklı gezi, yemek yarışması ve yemek-sohbet vb. türlere ayrılabilen ve gastronomiyi konu alan yayınlar, ulusal ve uluslararası düzeylerde milyonlarca izleyiciye ulaşmaktadır. Eğlenceyi ve eğitimi aynı formatta vermeye çalışan bu programlar yemek reçeteleri ve tariflerini bir hikâye kurgusu içerisinde vermekte ve bunları canlı olarak uygulamaktadır. Bu sayede izleyicilerde konuya ilişkin güdülerin harekete geçebileceği düşünülmektedir (Kurtçu, 2015). Görsel medyanın kitlesel hale gelmesiyle birlikte giderek yaygınlaşan ve popüler kültürün bir aracı haline gelen televizyon yayınları gençleri etkilemeye devam etmektedir. Literatürdeki bilgilerden hareketle TV yemek programlarına ilişkin aşağıdaki araştırma sorularına cevap aranmıştır;

Soru 1: Gençlerin TV yemek programlarına ilişkin popüler kültür algıları nasıldır?

Soru 2: TV yemek programlarının gençlerin eğitim ve meslek tercihleri üzerinde etkisi var mıdır?

\section{ARAŞTIRMA YÖNTEMI}

Araştırmada nitel araştırma yöntemleri, veri, toplama aracı olarak ise odak grup görüşmesi kullanılmıştır. Konuya ilişkin detaylı bilgi almak ve farklı veriler arasında karşılaştırma yapabilmek amacıyla odak grup görüşmesinden yararlanılmıştır. Bir nitel veri toplama tekniği 
olan odak grup görüşmeleri kendine has bazı özellikleriyle ön plana çıkmaktadır. Odak grup görüşmeleri (Çokluk vd., 2011);

- Önceden belirlenmiş yönergeler (kurallar) çerçevesinde gerçekleştirilir.

- Görüşülen kişilerin öznelliklerini ön planda tutar.

- Katılımciların söylemine ve bu söylemin toplumsal bağlamına dikkat eder.

Sosyal bilimlerde sıklıkla kullanılan odak grup görüşmesinin (Seyidoğlu, 2003) amacı, araştırılan konuyla ilgili olabilecek kişilere sorulan sorular neticesinde bilgiler almaktır (Aziz, 2013). İnteraktif bir ortamda gerçekleşen görüşmelerde bir bireyin verdiği cevap gruba mensup diğer bireylerin yanıtlarını şekillendireceği için oldukça yararlı bir yöntemdir. Bu durum araştırmacıların daha çok fikre ulaşmalarına ve daha zengin veriler elde etmelerine zemin hazırlamaktadır (Yıldırım ve Şimşek, 2005). Görüşmelerde açık uçlu ve derinlemesine bilgi gerektiren sorulara ağırlık verilmektedir. Çünkü araştırmacılar katılımcıların görüşlerine ilişkin derinlemesine bilgi elde etme arayışındadır (Baş vd., 2008). Bu bağlamda literatür taraması ve uzman (3 turizm, 2 gastronomi, 2 aşçı olmak üzere toplam 7) görüşleri neticesinde 12 sorudan oluşan bir soru seti oluşturulmuştur. Görüşmeye alınacak öğrenciler amaçlı örnekleme yöntemiyle belirlenmiştir. Bu örnekleme biçiminde araştırmacılar bilgi, deneyim ve gözlemlerinden hareket ederek çalışmanın amaçlarına uygun bir şekilde kendi değerlendirmeleriyle örneklemi belirlemektedir (Ural ve Kılıç, 2006). Bu çalışmada İstanbul Esenyurt Üniversitesi Meslek Yüksekokulu Aşçılık programı öğrencilerinden seçilen 16 kişi odak grup görüşmelerine dâhil edilmiştir. Birinci oturuma katılan öğrenciler ikinci sınıf öğrencilerinden ( 4 kız, 4 erkek) oluşmakta iken, ikinci oturuma katılan öğrenciler birinci sınıf öğrencilerinden (5 kız, 3 erkek) oluşmaktadır.

\section{Veri Toplama Süreci}

Araştırmada veriler iki grup ve sekiz kişiden oluşan, iki farklı ve paralel görüşme sonucu elde edilmiştir. Grup görüşmeleri raportör ve moderatörden oluşan iki kişilik ekip tarafından gerçekleştirilmiştir. A ve B salonlarında gerçekleştirilen görüşmelerde A salonunda iki (bir moderatör, bir raportör) araştırmacı yer alırken, B salonunda bir araştırmacı ve bir gönüllü uzman (bir moderatör, bir raportör) yer almıştır. A salonundaki görüşme 51 dakika 45 saniye sürerken, B salonundaki görüşme ise 51 dakika 59 saniye sürmüştür. Sürelerin birbirine yakın olması araştırma planının ve denek gruplarının doğru seçildiği konusunda fikir vermektedir. Görüşme öncesinde katılımcıların " $U$ " düzeninde oturtulmaları planlansa da oturumlar fiziki problemler nedeniyle sınıf düzeninde gerçekleştirilmiştir. Görüşmeler esnasında soru veya görüşlerini not alabilmeleri için katılımcıların her birine (16 kişi) kâğıt ve kalem verilmiştir. Görüşmelerden beklenilen verilerin elde edilmesi için görüşmelerin rahat, samimi ve sessiz bir ortamda gerçekleşmesine azami özen gösterilmiştir. Görüşmelerde soru cevap kısmına geçilmeden önce katılımcılara çalışmanın amacı ve önemi bağlamında bu toplantıda olma sebepleri açıklanmıştır. Katılımcıların kendilerini kısa kısa tanıtmaları ile veri toplama süreci başlamıştır. Çalışmanın amacına uygun cevapların elde edilebilmesi için soruların açık ve anlaşılır bir şekilde sorulmasına özen gösterilmiştir. Veri kayıplarının önüne geçmek ve araştırmanın güvenilirliği sağlamak amacıyla görüşmeler ses kayıt yöntemiyle kayıt altına alınmıştır. Analiz sürecinden önce ise ses kayıtları bilgisayar programı yardımıyla yazılı metin haline getirilmiştir. 


\section{Verilerin Analizi}

Veriler içerik analizi ile çözümlenmiştir. Bu analiz tekniği verilerin içinden yenilenebilir ve çıkarım yapmaya uygun bir araştırma tekniğidir (Aziz, 2013). Bu yöntem, çok geniş veri setlerinin kategoriler altında sistematik hale getirilmesine dayanmaktadır. Kategoriler literatür taraması, uzman görüşü ve araştırmacı ekibin deneyimlerinin yardımıyla belirlenmektedir. İçerik analizinin tahmin ve çıarım kabiliyeti yüksektir. Bu kabiliyet analizin deneysel ve açılayıcı rolüyle elde edilmektedir. Kategorileştirilmiş veri setleri daha basit ve sistematik bir hal almaktadır. Bu analiz şeklinde altı temel beklentinin sağlanması esastır (Stemler, 2000; Krippendorff, 2004). Bu beklentiler Tablo 1'de verilmektedir.

Tablo 1. İçerik Analizinden Beklentiler ve Araştırmadaki Yanıtları

\begin{tabular}{ll}
\hline İçerik Analizinden Beklentiler & \multicolumn{1}{c}{ Bu Çalışma } \\
\hline Hangi veriler analiz edilecek? & $\begin{array}{l}\text { İstanbul Esenyurt Üniversitesi Meslek Yüksekokulu } \\
\text { Aşçlı Programı öğrencilerinden Ocak 2019 } \\
\text { tarihinde odak grup görüşmesi sonucu elde edilen } \\
\text { veriler }\end{array}$ \\
\hline \multirow{2}{*}{ Veriler nasıl tanımlanır? } & $\begin{array}{l}\text { Öğrencilerin TV yemek programlarının popüler } \\
\text { kültür algısı ve kendilerine olan etkilerine yönelik } \\
\text { görüşleri }\end{array}$ \\
\hline Veriler hangi gruptan toplandı? & $\begin{array}{l}\text { İstanbul Esenyurt Üniversitesi Aşçıllı programı 1 ve } \\
\text { 2. sınıf öğrencileri (8+8=16) }\end{array}$ \\
\hline \multirow{3}{*}{ Verilerin analiz edileceği bağlam nedir? } & $\begin{array}{l}\text { İki ayrı gruptan toplanan verilere ilişkin oluşturulan } \\
\text { temalar arasındaki ilişkilerin tanımlanması (Popüler } \\
\text { Kültür ve Gastronomi) }\end{array}$ \\
\hline \multirow{3}{*}{ Hangi analizler kullanılacak? } & $\begin{array}{l}\text { Görüşme içeriklerine dair kelime bulutları, ilişki } \\
\text { tarayıcıları ilişki haritaları ve kodların birlikte } \\
\text { çalışma modelleri }\end{array}$ \\
\hline \multirow{2}{*}{ Sonuçların amacı nedir? } & $\begin{array}{l}\text { Son yıllarda yaygınlık kazanan TV yemek } \\
\text { programlarının popüler kültür algısı ve gençler } \\
\text { üzerindeki etkileri }\end{array}$ \\
\hline
\end{tabular}

Veriler İstanbul Esenyurt Üniversitesi Aşçlık Programı öğrencilerinden odak grup görüşmesi sonucunda elde edilmiştir. Özellikle son yıllarda bütün dünyada olduğu gibi Türkiye'de de TV yemek programlarının popülerlik kazanması bu çalışmada veri toplanan hedef kitleyi belirlemiştir. Çünkü programların sahip olduğu popülerlik gençlerin aşçllık veya gastronomi bölümlerini tercih etmelerini doğrudan veya dolaylı olarak etkilemektedir. Çocuklarının bu tür bölümlerde okumasını istemeyen ebeveynlerin fikirleri bile yemek programlarından sonra değişmeye başlamıştır. Burada TV ile birlikte kitlesel hale gelmiş görsel medyanın popüler kültür ve toplum üzerindeki etkileri net bir şekilde görülmektedir.

Tablo 2. Analiz Kapsamindaki Tema ve Kodlar

\begin{tabular}{lll}
\hline Aşama & Temalar & Kodlar \\
\hline Birinci Adım & Popüler Kültür & Moda, Marka, İmaj, Statü, Fayda, Estetik \\
\hline Íkinci Adım & Gastronomi & $\begin{array}{l}\text { Mesleki Kazanım, Mutfak Bilgisi, Kültür, Yöresel Mutfak, } \\
\text { Dünya Mutfağı, Tarih }\end{array}$ \\
\hline
\end{tabular}


Öğrencilerden elde edilen verilerin analizinde MAXQDA nitel analiz programının güncel sürümünden yararlanılmıştır. İlgili program harita ve görseller yardımıyla fikirleri netleştirmek ve kategoriler ile özellikler arasındaki varsayımsal ilişkileri anlamak için kullanılmaktadır (Azzopardi ve Nash, 2016; Kuckartz ve Radiker, 2019). Her iki görüşmeden elde edilen verilerin tamamı analize dâhil edilmiştir. Analiz sürecinin ilk adımında popüler kültür ve gastronominin ön planda olduğu kod ve temalar oluşturulmuştur. Çalışmada ana temalar olarak popüler kültür ve gastronomi kavramlarının altında kodlar belirlenmiştir. Tablo 2'de görülen kodlar literatür desteği ve uzman görüşleri neticesinde belirlenmiştir. Popüler kültür temasının altındaki kodlar popüler kültürün ortaya çıkıp gelişmesinden sonra oluşan popüler kültür boyutlarından oluşmaktadır. Bu kodlar genellikle literatür desteğiyle oluşturulmuştur. Gastronomi temasının alt kodları ise TV yemek programlarının aşçllı veya gastronomi eğitimi noktasında gençler üzerindeki olası etkileri dikkate alınarak oluşturulmuştur. Gastronomi temasının altındaki kodların oluşturulması sürecinde ise uzman görüşlerine yer verilmiştir. Son olarak belirlenen temalar MAXQDA programına kodlanmış, devamında ise elde edilen veriler cümleler halinde ilişkili oldukları tema ve kodlara aktarılarak analizler gerçekleştirilmiştir.

\section{BULGULAR}

Araştırmada elde edilen veriler oluşturulan tema ve kodlar yardımıyla dört farklı aşamada analiz edilmiştir. İlk olarak temalara kodlanan görüşme içerikleri için kelime bulutu analizi yapılmıştır. İkinci aşamada tema ve kodlar arasındaki aynı verinin içerisinde geçme durumuna bağlı olarak oluşan ilişki tarayıcılarına ilişkin analiz gerçekleştirilmiştir. Üçüncü aşamada bütüncül bir bakış açısı sağlamak için kodların ilişkilerini gösteren bir ilişki haritası oluşturulmuştur. Bu çerçevede haritadaki çizgilerin nitelikleri değerlendirilmiş ve kodlar arasındaki ilişkiler ve bunların nedenleri yorumlanmıştır. En son aşamada ise temaların ve onlara bağlı alt kodların birlikte çalışmalarını gösteren modellere yer verilmiştir. Analiz kapsamında her kategorinin bulguları MAXQDA yardımıyla şekiller halinde verilerek raporlama yapılmıştır.

Veri analiz sürecinin ilk aşamasını oluşturan kelime bulutu Şekil 1'de verilmektedir. Bu analiz, kelimelerin verilerde geçme sıklıklarına bağlı olarak şekillenmektedir. Şekil 1'de kelimelerin büyüklüğü verilerin içerisindeki geçme sıklığına göre şekillenmekte olup, merkezde yer alan kelime en büyük sıklığa sahip kelimedir. Bu çalışma kapsamında kullanılan kelimelerin daraltılması için frekans olarak "10" değeri en alt değer olarak belirlenmiş ve 10'nun üzerinde frekans değerine sahip olan kelimeler kelime bulutuna dâhil edilmiştir. İkinci aşamada ise konuyla ilgili olmayan kelimeler (yüklemler, bağlaçlar, zamirler vb.) kelime bulutundan çıkarılmıştır. 
1. Oturum-2. Sinıflar

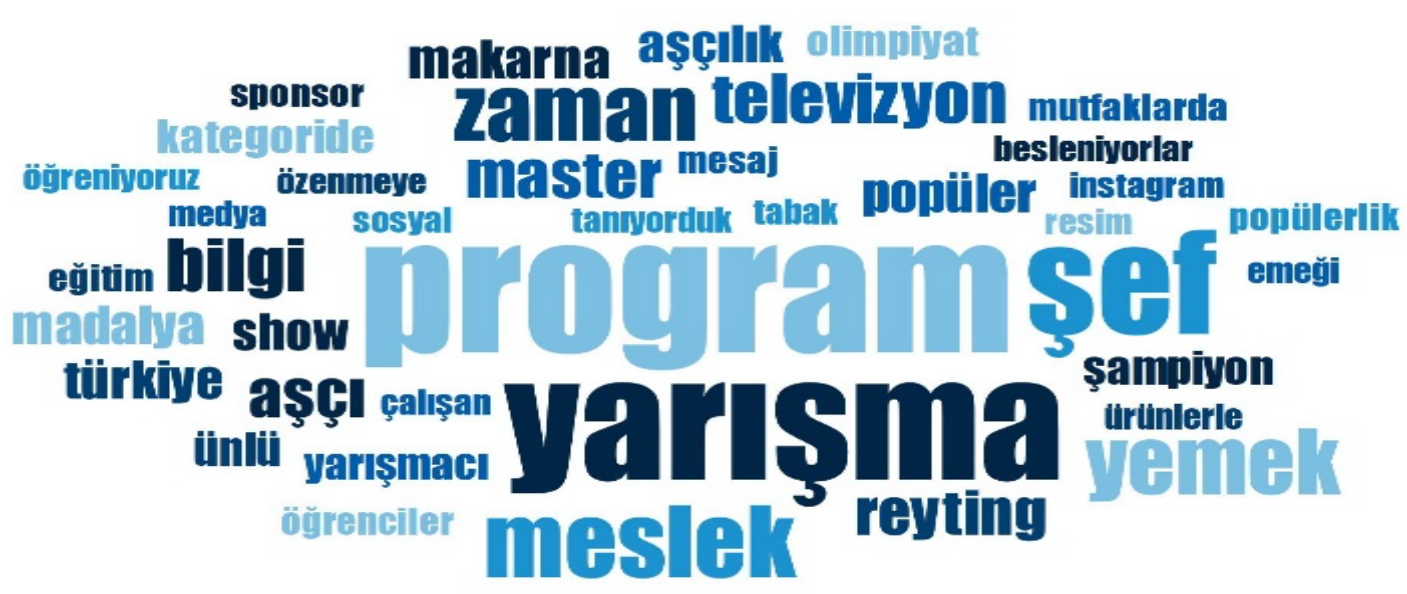

2. Oturum-1. Siniflar

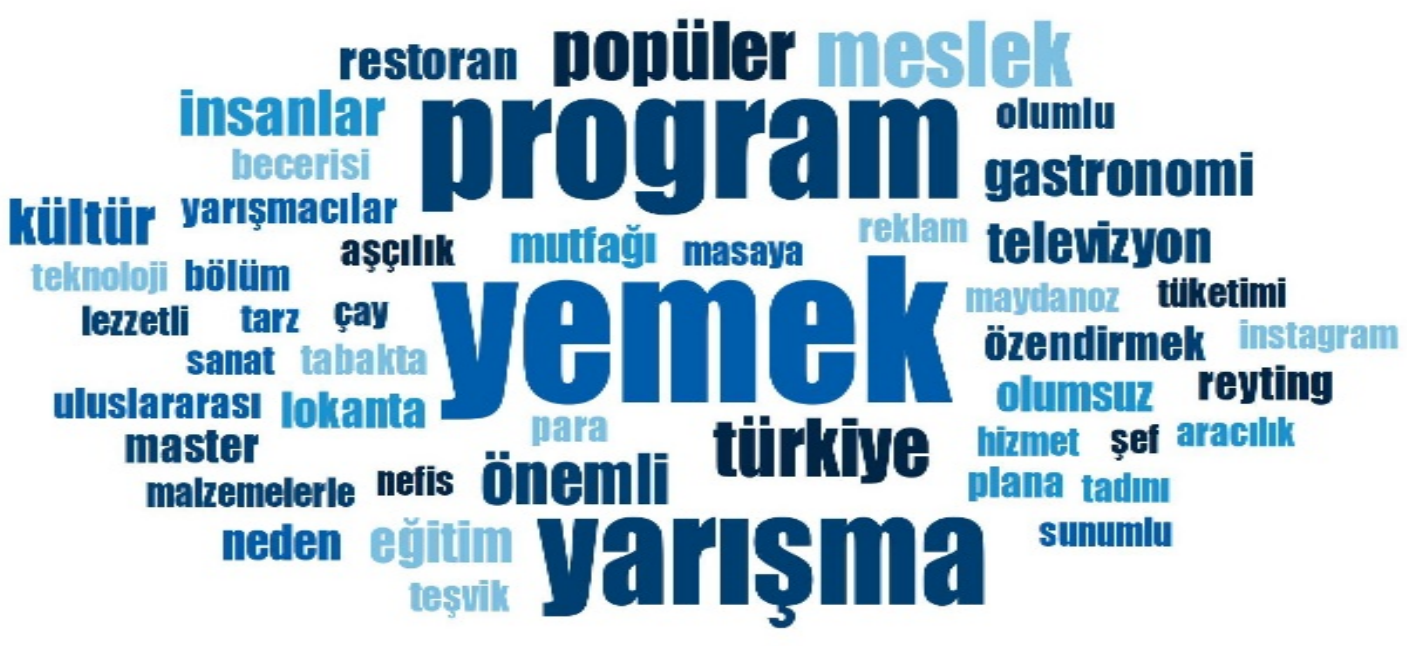

Şekil 1. Görüşme İçeriklerine Ait Kelime Bulutu

Kelime bulutu analizi veri toplanan her iki grup görüşme için ayrı ayrı yapılmıştır. Bu sayede odak grup görüşmesinin doğası gereği farklı grupların fikirlerinin karşılaştırılması ve farklı eğitim deneyimine sahip öğrenciler arasındaki farklılıkların belirlenmesi planlanmıştır. Birinci sınıflarla yapılan görüşmelerde en sık tekrarlanan kelime "yemek"tir. Yemek dişında "program", "yarışma", "meslek", "popüler", "Türkiye", "gastronomi", "televizyon" ve "kültür" gibi kelimeler en sık geçen kelimeler olarak öne çıkmaktadır. İkinci sınıflarda en çok tekrar edilen kelime "program" olmuştur. Program dışında, "yarışma", "yemek", "reyting", "şef", "zaman", "bilgi", "aşçı" ve "aşçlık" gibi kelimeler geçmektedir. Bu yönüyle ikinci sınıflar daha çok programın gençler üzerindeki eğitici yanlarına vurgu yapan kelimeler kullanırken, birinci sınıflar programların popüler kültür ürünü olarak gelişimlerini öne çıkaran kelimelere vurgu yapmışlardır. 


\section{Oturum-2. Siniflar}

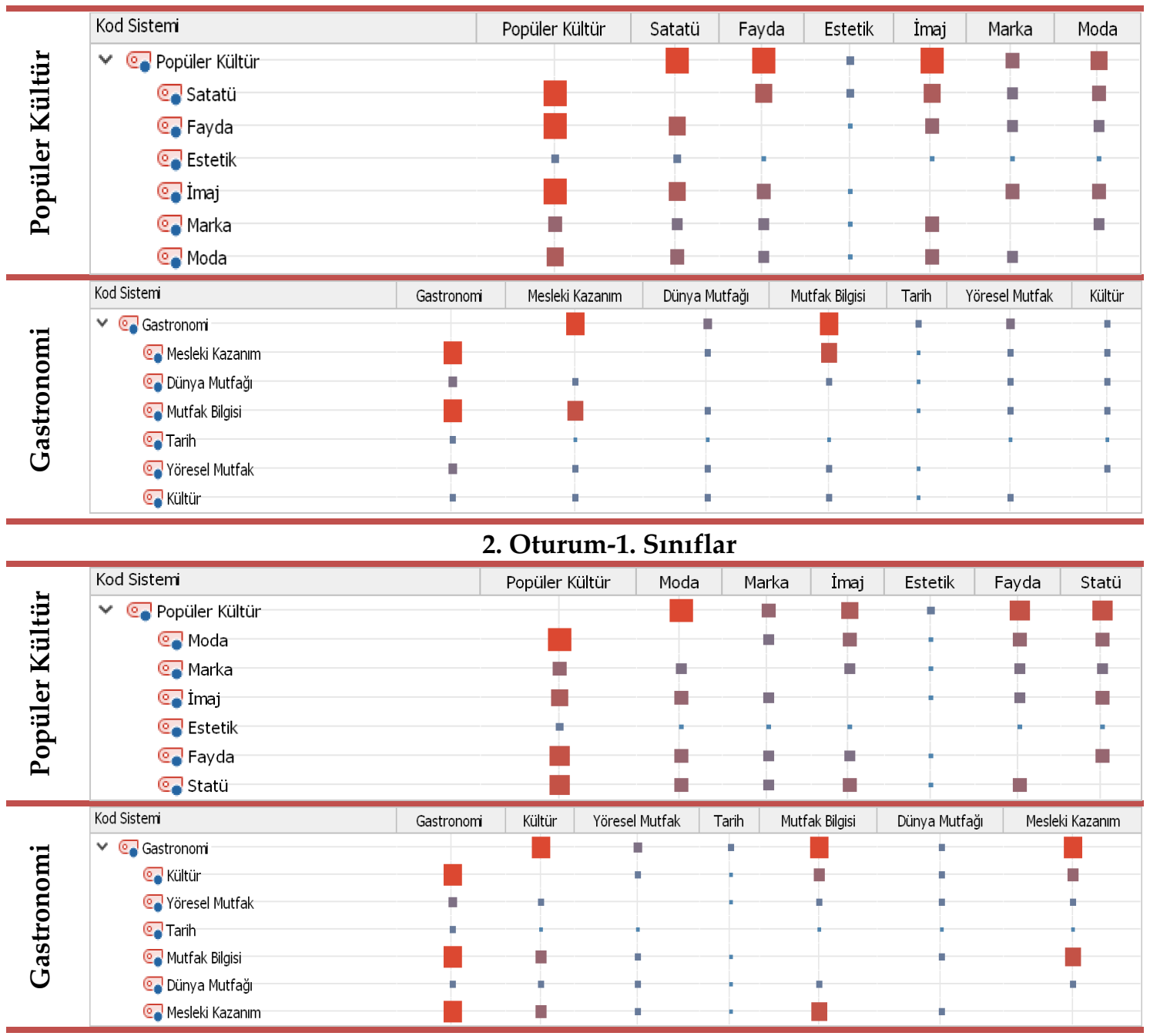

Şekil 2. Kod ve Temaların İlişki Tarayıcıları

Popüler kültür temasının alt kodlarla ilişkisinde gruplar arasında bazı farklıklar söz konusudur. İkinci sınıf öğrencileri TV yemek programlarını popüler kültür bağlamında en çok imaj, fayda ve statü bağlamında değerlendirmiştir. Birinci sınıf öğrencileri ise en çok moda bağlamında değerlendirmeler yapmıştır. Ancak statü ve fayda kodları da birinci sınıflar tarafından popüler kültürle birlikte kullanılmıştır. Kodların kendi aralarındaki ortak kullanımlarına bakıldığında ise moda, imaj, statü ve fayda kodlarının birlikte kullanıldığı görülmektedir. Estetik boyutunun ise her iki görüşme için popüler kültür teması ve diğer kodlarla birlikte çok sık kullanılmadığı söylenebilir.

Şekil 3 karmaşık gibi görünse de temelde basit bir mantığa dayanmaktadır. Kodlar arası ilişkilerde ilişkinin yoğunluklarına göre değerlendirilmesi şeklin devamında yer almaktadır. Üç kademe ilişki şekil üzerinde gösterilirken, düşük ilişkiler (4. kademe) belirtilmemiştir. 

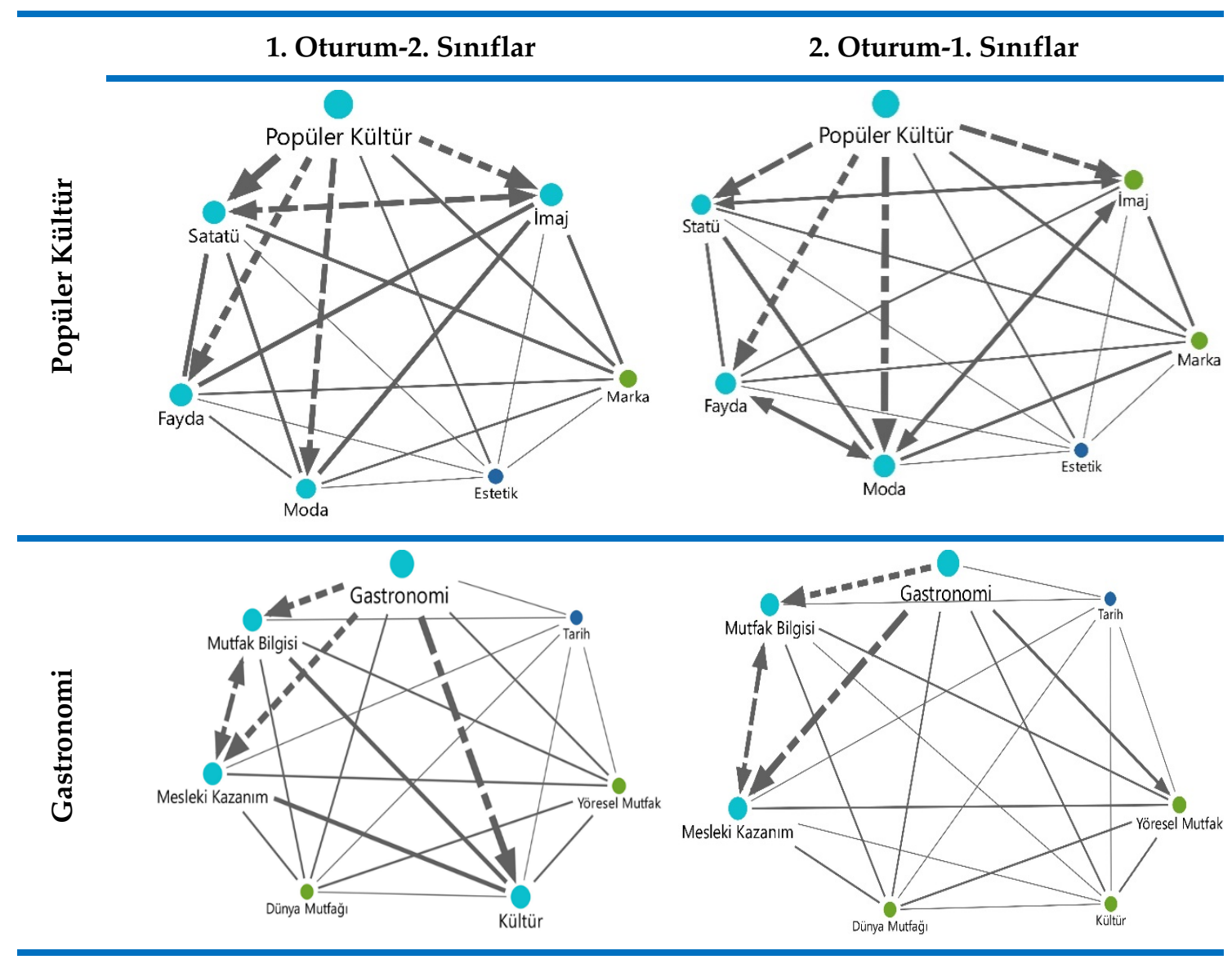

İlişki Yoğunluğu (Düşükten Yükseğe doğru)

Şekil 3. Kod ve Temalara Ait İlişki Haritaları

Kısaca Şekil 3 kodlar arası geçiş ve buna bağlı olarak bu kodların birbirleriyle ilişkisini yansıtmaktadır. Analizler her iki görüşme ve popüler kültür ile gastronomi temaları için ayrı ayrı yapılmıştır. Birinci sınıfların ilişki haritasında gastronomi temasının en güçlü ilişkisi mesleki kazanım koduyla olmuştur. Uzun ve kısa kesik çizgilerle verilen bu ilişkinin şiddeti "7/10" olarak belirlenmiştir. Bundan sonra en güçlü ilişkiler gastronomi teması ile mutfak bilgisi kodu arasında gerçekleşmiştir. Kısa kesik çizgilerle gösterilen bu ilişkilerin şiddeti “6/10"'dur. Uzun kesik çizgilerle belirtilen ve üçüncü düzey bir ilişkiyi veren "(4/10)" ve mesleki kazanım ile mutfak bilgisi kodları arasındaki ilişki de haritada gösterilmiştir. Bunun dışındaki ilişkiler düşük kabul edilmiş ve düz çizgilerle gösterilmiştir. İkinci sınıfların gastronomi temasında da benzer ilişkiler vardır. Tek fark kültürün de bu ilişki içerisinde gastronomi temasıyla mesleki kazanım ve mutfak bilgisinden daha fazla ilişkili çıkmış olmasıdır.

Popüler kültür temasının ilişki haritalarında ise moda belirleyici role sahip koddur. Birinci sınıflar için (ikinci görüşme) moda popüler kültürle en ilişkili koddur (popüler kültür alt boyutu). Uzun ve kısa kesik çizgilerle verilen bu ilişkinin şiddeti "7/10" olarak belirlenmiştir. İkinci sınıflarda ise statü, imaj ve fayda kodları popüler kültürle ilişkili çıkmaktadır. İkinci sınıf öğrencilerinin görüşlerine göre TV yemek programları bağlamında bu üç kodun popüler kültürle ilişkisi yakın, imaj ve statü kodlarının birbiriyle ilişkisi ise yüksektir. Bu iki kod arasında uzun kesik çizgilerle belirtilen ve üçüncü düzey bir ilişkiyi veren "(5/10)" bir ilişki mevcuttur. Birinci sınıfların kodlar arasındaki ilişkileri güçlü ilişki gösteren üç düzey ilişkinin de altında kalmıştır. 
Şekil 4'te kodlara ait ilişki tarayıcılarına ilişkin model yer almaktadır. Bu modelde araştırmada ilişkileri test edilen kodların yanı sıra bu kodları oluşturan iki ana temaya da yer verilmiştir. Ayrıca analiz her iki odak grup görüşmesi için ayrı ayrı yapılmıştır. Öncellikle Şekil 4'te yansıyan en önemli bulgu beklendiği gibi TV yemek programlarından kaynaklı popüler kültür ve gastronomi temalarının arasında güçlü bir ilişkinin ortaya çıkmış olmasıdır. Her iki oturumda popüler kültür boyutlarından olan "estetik" kodu düşük ilişkileri nedeniyle model dışı kalmıştır. Gastronomi temasında ise ikinci sınıflarda mesleki kazanım, mutfak bilgisi dışındaki dört kod düşük ilişkileri nedeniyle modelde yer almamaktadır. Birinci sınıflarda ise bu iki kod gibi kültür kodu da güçlü ilişkileri nedeniyle modelde kalmıştır.

\section{Oturum-2. Sinıflar}

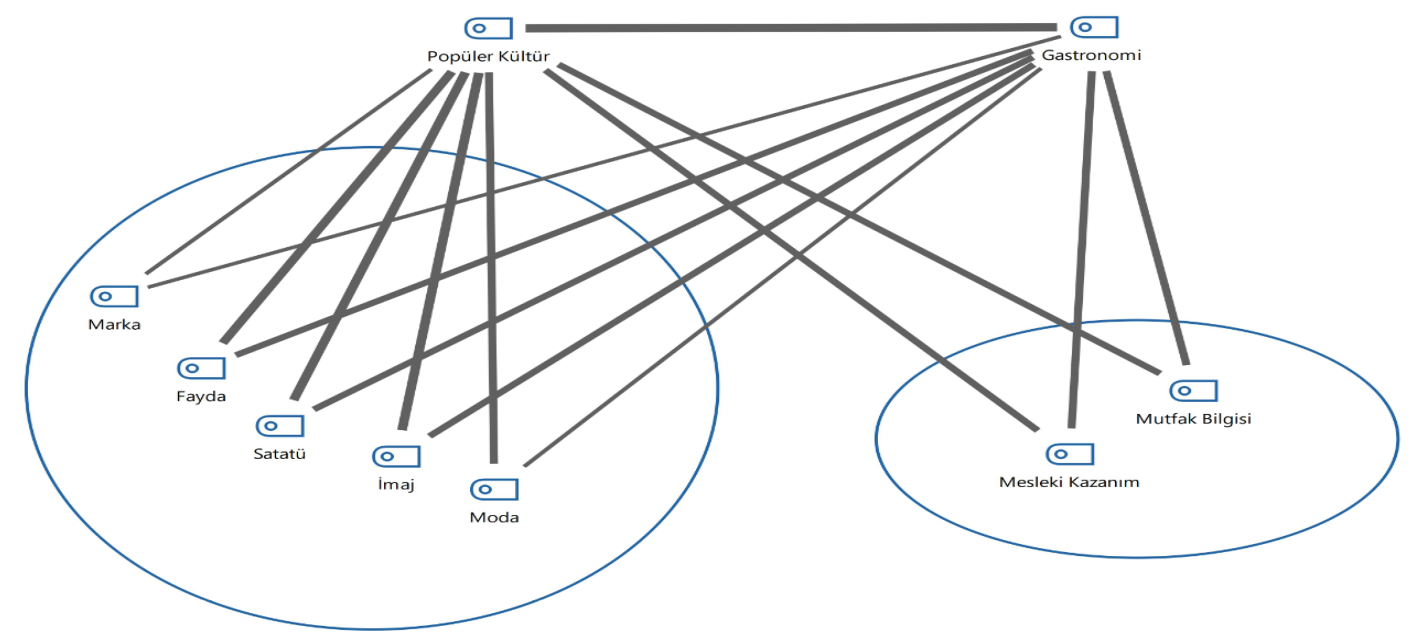

2. Oturum-1. Sinıflar

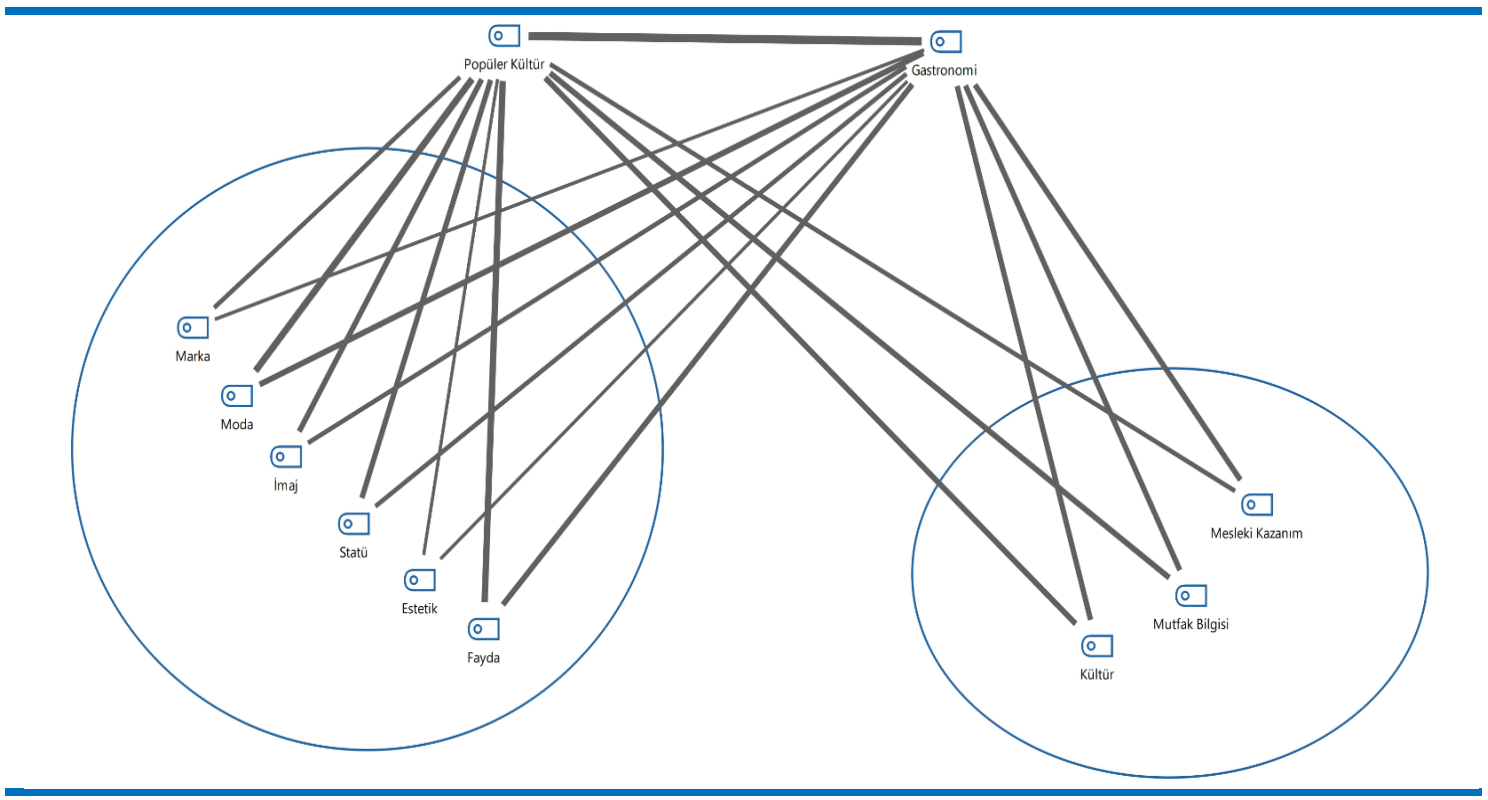

Şekil 4. Kodların Birlikte Çalışma Modeli 
Birlikte çalışma modelinin yer aldığı Şekil 4'e göre temaların alt kodlarıyla olan etkileşimleri diğer analizlerle benzerlik taşımaktadır. Ancak temaların birbirleri ve diğer temanın alt kodlarıyla olan ilişkileri model analizini anlamlı hale getirmektedir. Birinci oturumda (2. Sınıflar) popüler kültürün gastronomi temasının alt kodlarıyla (mesleki kazanım ve mutfak bilgisi) yakın bir ilişkisi mevcuttur. Gastronomi temasının ise en güçlü ilişkisi imaj boyutuyla iken, en zayıf ilişkisi marka boyutuyladır. İkinci oturumda ise popüler kültür teması gastronomi alt kodlarından kültürle ilişkili çıkarken, en az mesleki kazanım boyutuyla ilişkili çıkmıştır. Gastronomi teması ise en çok moda ve fayda kodlarıyla ilişkili çıkmıştır.

\section{TARTIŞMA}

TV programları, kültür endüstrisinin gelişmesiyle birlikte popüler kültürün önemli araçlarından biri olarak gelişmeye başlamıştır. Bu sadece TV ile sınırlı kalmayıp, bütün görsel medya araçları için yaygın hale gelmiştir (Kırık, 2018). Alemdar ve Erdoğan (2005) TV ve basını teknolojik çoğaltım ve seri üretimle birlikte popüler kültürün kaynağı olarak ifade etmekte, bunların olmaması durumunda popüler kültürün de olmayacağını belirtmektedir. Bu çalışmanın sonuçları da burada ifade edilen genel görüşü desteklemektedir. Nitekim Yumlu (1990) bütün medya bağlamında kitle iletişim araçlarını "kültürün temel taşıyıcıları" olarak ifade etmektedir.

TV yemek programları literatürde de yer aldığı gibi popüler kültürün bazı temel boyutlarında kendini net bir şekilde göstermektedir. Gençler genel olarak yemek programlarının popüler kültüre statü bağlamında hizmet ettiğini vurgulamaktadır. Baran ve Baran (2014) popüler kültür bağlamında TV programlarının tüketicilere sosyal statü ve sınıfa dair önemli mesajlar verdiğini ifade etmektedir. Popülerliğin temel unsurlarından biri olan modaya uymak adına TV programları yapılmaktadır. Özellikle popülerliğin moda ile etkileşimli olduğu bir ortamda, Türkiye'de TV yemek programlarında özellikle 2018 ve sonrasında önemli bir artış yaşanmıştır. Alemdar ve Erdoğan (2005) bu değerlendirmeleri destekleyecek şekilde modayı takip etmenin popüler bir pratik olduğunu ifade etmektedir. Türkiye'deki gençler TV yemek programlarının yaygınlaşmasında modaya uymanın önemli bir pratik olduğunu düşünmektedir. Ancak TV programları popüler kültür için önemli bir pratik iken (Nazik ve Bayazit, 2004; Hebdige, 2004; Şimşek, 2010), bu çalışmanın sonuçlarına göre Türkiye'deki TV yemek programları için böyle bir durum söz konusu değildir.

Literatür popüler kültürün baskın bir şekilde imaj üzerine kurulu bir yapıya sahip olduğunu belirtmektedir. Popüler kültürün bir yansıması olarak imaj; geliştirilen bütün tutumların ve sergilenen davranışların ötesindedir. Kitle iletişim araçları ve görsel medya hayatın birçok alanında popüler kültürün bir aracı olarak imaj oluşturmaya neden olmaktadır (Coşgun, 2012). İmajın amacı hâkim fikir olduğunda, toplumsal fayda beklentisi ikinci planda kalmaktadır. Özellikle popüler kültürün bir aracı olarak imajı ilke edinen TV yemek programların toplumsal faydaları azalmakta ve reyting amacıyla programların sayısında artış yaşanmaktadır.

Herhangi bir program formatının reyting alması durumunda, farklı platformlarda benzer nitelikteki programların giderek çoğaldığına rastlanılmaktadır. Giderek artan bu programlar bilgi ve kazanım sağlamaktan uzak, bireyleri memnun etmek, ilgilerini dağıtmak veya satışları arttırmak gibi amaçlar güdülmektedir (Güllüoğlu, 2012). Ancak popüler kültürün etkilerini taşıyan TV yemek programlarında bu görüşün tersine sonuçlar elde edilmiştir. Öğrenciler reyting amacıyla dahi olsa yapılan bu programların mutfak bilgisi ve mesleki kazanım bağlamında kendilerine olumlu yansımaları olduğu görüşündedir. 


\section{SONUÇ ve ÇIKARIMLAR}

TV yemek programları gençleri birçok açıdan etkilemektedir. Özellikle bu tür programlarda toplumu etkilemek için ortak değerler üzerinden mesajlar verilmektedir. TV yemek programlarında kültür veya yöresel mutfak vurguları çok sık yer almaktadır. Bunun bir yansıması olarak kültür, bu programların önemli bir çıktısı olarak vurgulanmıştır.

Görsel medya ve popüler kültürün ortak bir değer veya argüman olarak karşı tarafa bir mesaj biçiminde bilgi, beceri veya ustalık isteyen sade ürünler sundukları bilinmektedir (Horkheimer ve Adorno, 1996). Bu çalışmanın sonuçlarına göre, gençler TV yemek programlarının mutfak bilgisi konusunda önemli katkılar sağladığını vurgulamaktadır. Gençler bu katkıları nedeniyle yarışmaları takip ettiklerini ifade etmektedir. Popüler kültürün bir aracı olarak TV yemek programları, toplumun konuyla ilgili düşüncelerini değiştirerek farklı düşünmelerine aracılık etmektedir. Örneğin birçok öğrencinin ailesi çocuklarının aşçllık eğitimi alma ve gelecekte bu mesleği yapmaya ilişkin taleplerini ret ederken, bu yarışmaların popüler hale gelmesiyle bu görüşlerini terk etmiş ve çocuklarını özendirmiştir. Postman (1994) televizyonla dayatılmaya çalışılan popüler kültürün aracı olan ürünlerin toplumu düşünmekten alıkoyan, gözleri boyayan ve zorlu bir süreci hayali güzelliklerle sunan bir hayat vadettiğini ortaya koymaktadır. Ebeveynlerin çocuklarıyla ilgili fikirlerinin değişmesinde Postman'ın görüşünün etkilerini görmek mümkündür.

Türkiye'deki TV yemek programları; temel felsefeleri, reyting kaygıları ve 2018 yılından sonraki sayısal artışlarıyla popüler kültürün en önemli araçları haline gelmiştir. Kitle iletişim araçlarındaki bu programlar sadece algı, tutum ve davranışları güçlendirme amacına hizmet etmemekte, reyting, konu tespiti ve kamuoyu oluşturma gibi amaçlarla da hareket etmektedir (Bourdieu, 1997). Son yıllarda giderek artan programların reyting odaklı olduğu söylenebilir. Çünkü yarışmaların formatında eğitici bilgiler olsa da yarışmacıların kaos ve kavgadan beslendikleri bir konsept takip edilmektedir. Yarışmaların doğasında rekabet olmakla birlikte, bu rekabet kavga, giybet, kulis ve kaostan ziyade etik ve ahlaki değerler ölçüsünde sürdürülebilir kllınabilir.

\section{Sınırlıklar ve Gelecek Çalışmalar}

Çalışma, TV yemek programlarının popüler kültür algısı ve gençler üzerindeki etkileriyle ilgili güncel ve önemli sonuçlar sunmakla birlikte, bazı önemli kısıtlar da içermektedir. Her çalışmada olanın aksine maliyetle ilgili kısıtlar yaşanmazken, zaman anlamında bazı kısıtlarla karşılaşılmıştır. Özellikle veri toplama sürecinden kısa bir süre sonra COVID-19 vakalarının Türkiye'de de görülmeye başlanması ve akabinde getirilen kısıtlamalar çalışmanın analiz, raporlama ve yazım sürecini uzatmıştır.

Ayrıca, odak grup görüşmesi nitel araştırma teknikleri veri toplama araçları içerisinde güvenilir bir yöntem olmasına rağmen, katılımcı grupların içerisindeki bazı katılımcıların çalışmanın amaçları ve soruları anlama noktasında problem yaşadıkları söylenebilir. Özellikle bir grubun olması ve zamanla ilgili problemler bu kişilerle ilgilenmeyi zorlaştırmaktadır. Bu bakımdan gelecekte aynı konu üzerinde farklı nitel araştırma yöntemleriyle de çalışılabilir. Popüler kültür konusunda algı, tutum ve davranış eğilimi gibi unsurların belirleyici olabileceği düşüncesiyle gelecek araştırmalar için konunun nicel araştırma teknikleriyle de çalışılması önerilmektedir. 


\section{KAYNAKÇA}

Alemdar, K. ve Erdoğan, İ. (2005). Öteki Kuram: Kitle İletişim Kuram ve Araştırmalarının Tarihsel ve Eleştirel Bir Değerlendirmesi. Ankara: Erk Yayınları.

Aziz, A. (2013). Sosyal Bilimlerde Araştırma Yöntemleri ve Teknikleri. Ankara: Nobel Yayınları.

Azzopardi, E. and Nash, R. (2016). A Framework for Island Destination CompetitivenessPerspectives from The Island of Malta, Current Issues in Tourism, 19(3): 253-281.

Baran, T. ve Baran, S. (2014). Televizyon Programlarl, Sembolik Tüketim ve Toplumsal Yansımaları, Karamanoğlu Mehmetbey Üniversitesi Sosyal ve Ekonomik Araştırmalar Dergisi, (3): 171175.

Baş T., Çamır, M. ve Özmaldar, B. (2008). Nitel Araştırma Yöntemleri. Ankara: Seçkin Yayıncılık.

Bourdieu, P. (1997). Televizyon Üzerine. (Çeviren, T. Ilgaz), İstanbul: Yapı Kredi Yayınları.

Boyle, R. and Kelly, L. (2010). The Celebrity Entrepreneur on Television: Profile, Politics and Power, Celebrity Studies, 1(3): 334-350.

Coşgun, M. (2012). Popüler Kültür ve Tüketim Toplumu, Batman Üniversitesi Yaşam Bilimleri Dergisi, 1(1): 837-850.

Çokluk Ö., Yılmaz K. ve Oğuz U. (2011). Nitel Bir Görüşme Yöntemi: Odak Grup Görüşmesi. Afyon Kocatepe Üniversitesi, Kuramsal Eğitimbilim Dergisi, 4(1): 95-107.

Ertopçu, İ. ve Görkem O. (2019). TV Yemek Programlarının Gastronomi Eğitimine Yansımaları, Türk Turizm Araştırmaları Dergisi, 3(4): 1501-1513.

Geçer, E. (2013). Medya ve Popüler Kültür: Diziler, Televizyon ve Toplum. İstanbul: Metemorfoz Yayıncilik.

Güllüoğlu, Ö. (2012). Bir Kitle İletişim Aracı Olarak Televizyonun Popüler Kültür Ürünlerini Benimsetme ve Yayma İşlevi Üzerine Bir Değerlendirme, Global Media Journal: Turkish Edition, 2(4): 64-86.

Hebdige, D. (2004). Altkültür Tarzın Anlamı. (Çeviren, S. Nişancı.), İstanbul: Babil Yayınları.

Horkheimer, M., ve Adorno, T. W. (1996). Aydınlanmanın Diyalektiğgi: Felsefi Fragmanlar II. Ol (Çeviren, O. Özügül), İstanbul: Kabalcı Yayınevi.

Judelson, S. (1997) Introduction: What is East-West Food?, (Editör.) S. Judelson: East West Food: Food from the Pacific Rim and Beyond, with 10 of the World's Hottest Chefs İçinde London: Hamlyn Press.

Kanık, İ. (2016). Küreselleşme Sürecinde Kültürel Melezleşme Örneği Olarak Yemek Kanalları ve Programları, Folklor Edebiyat, 22(86): 237-258.

Karaduman, N. (2017). Popüler Kültürün Oluşmasında ve Aktarılmasında Sosyal Medyanın Rolü, Erciyes Üniversitesi Sosyal Bilimler Enstitüsü Dergisi, (2): 7-27.

Kırık, A. M. (2018). Popüler Kültür ve Kültür Endüstrisi Bağlamında 'Yetenek Sizsiniz Türkiye' Program Formatına Yönelik Eleştirel Bir Analiz, Akdeniz İletişim, (30): 31-50.

Köksalan M. E. (2009). Küreselleşme Sürecinde Televizyon: Çok Kimliklilik ve Postmodern İzleyicilik. International Davraz Congress on Social and Economic Issues Shaping the World's Future: New Global Dialogue, 24-27 Eylül, Davraz-Isparta, ss. 2351-2366.

Kösoğlu, N. (1992). Millî Kültür ve Kimlik, İstanbul: Ötüken Yayınc1lı. 
Krippendorff, K. (2004). Content Analysis: An Introduction to Its Methodology. Thousand Oaks, CA: Sage Publishing.

Kuckartz, U., and Radiker, S. (2019). Analyzing Qualitative Data with MAXQDA. New York: Springer International Publishing.

Kurtçu, C. (2015). Türk Televizyon Yayıncılığında Gastronomi Dünyasının Yeri, Yayınlanmamış Yüksek Lisans Tezi, Marmara Üniversitesi Sosyal Bilimler Enstitüsü, İstanbul.

Matwick, K. and Matwick, K. (2014). Storytelling and Synthetic Personalization in Television Cooking Shows, Journal of Pragmatics, (71): 151-159.

Nazik, H. ve Bayazit, A. (2004). İnsan İlişkileri ve İletişim. İstanbul: Yapa Yayınları.

Postman, N. (1994). Televizyon Öldüren Eğlence. İstanbul: Ayrıntı Yayınları.

Seyidoğlu H. (2003). Bilimsel Araştırma ve Yazma El Kitabı. İstanbul: Kuriş Matbaası.

Shrum, L. J. (2009). Media Consumption and Perceptions of Social Reality: Effects and Underlying Processes. (Editör) J. Bryant ve M. B. Oliver: Media Effects: Advances in Theory and Research İçinde (pp.50-73), 3rd Edition New York: Psychology Press.

Stemler, S. (2000). An Overview of Content Analysis, Practical Assessment, Research, and Evaluation, 7(17): 1-6.

Şenel, P., ve Yılmaz, H. (2017). Televizyonda Yayınlanan Gastronomi Konulu Gezi Programlarının Davranışsal Tatma Niyetine Etkisi, Balıkesir Üniversitesi Sosyal Bilimler Enstitüsü Dergisi, 20(38): 521-543.

Şentürk, Ü. (2007). Popüler Bir Kültür Örneği Olarak Futbol, Cumhuriyet Üniversitesi Sosyal Bilimler Dergisi, 31(1): 25-41.

Şimşek, Ş. (2010). Yaşam Tarzı Üzerinde Popüler Kültürün Belirleyiciliği ve Kitle İletişim Araçlarının Etkisi: Türkiye'de Punk Kültürü Örneği, Yayınlanmamış Yüksek Lisans Tezi, Selçuk Üniversitesi Sosyal Bilimler Enstitüsü, Konya.

Tezer, D. (2013). Televizyon-Kültür İlişkisi Bağlamında Popüler Kültürün Algılanış Biçimleri Kahramanmaraş Örneği, Yayınlanmamış Yüksek Lisans Tezi, Selçuk Üniversitesi Sosyal Bilimler Enstitüsü, Konya.

Ural A. ve Kılıç İ. (2006). Bilimsel Araştırma Süreci ve SPSS ile Veri Analizi. Ankara: Detay Yayıncılık.

Yıldırım, A. ve Şimşek, H. (2005). Sosyal Bilimlerde Nitel Araştırma Yöntemleri. Ankara: Seçkin Yayınları.

Yıldız, S., (2004). Televizyonlarda Yayınlanan Magazin, Eğlence ve Yarışma Türü Programların Toplumsal Kültür Üzerine Etkileri -Kırıkkale ve Ankara Örneği, Bilim ve Aklın Aydınlığında Eğitim Dergisi, (57): 173-178.

Yumlu, K. (1990). Kitle Illetişim Araştırmaları. İzmir: Ege Üniversitesi Basımevi. 